\title{
The role of temperature and photoperiod in diapause induction in the brassica leaf beetle, Phaedon brassicae (Coleoptera: Chrysomelidae)
}

\author{
XIAo-PIng WANG ${ }^{1}$, FAng-Sen XUE ${ }^{2}$, Yong-QIn TAN ${ }^{1}$ and Chao-Liang LEI ${ }^{1 *}$ \\ ${ }^{1}$ College of Plant Science and Technology, Huazhong Agricultural University, Wuhan 430070, P.R. China \\ ${ }^{2}$ Institute of Entomology, Jiangxi Agricultural University, Nanchang 330045, P.R. China
}

Key words. Chrysomelidae, brassica leaf beetle, Phaedon brassicae, photoperiod, reproductive diapause induction, temperature

\begin{abstract}
The brassica leaf beetle, Phaedon brassicae Baly (Coleoptera: Chrysomelidae), one of the pests infesting cruciferous vegetables in China and Japan, is a multivoltine species that oversummers and overwinters as an adult. The effects of both temperature and photoperiod on reproductive diapause induction were systematically investigated in this beetle. Under $16 \mathrm{~L}: 8 \mathrm{D}$, most of the beetles entered reproductive diapause at $12-30^{\circ} \mathrm{C}$, indicating that photoperiod played a crucial role in estivation diapause induction. Under 12L : 12D, all adults developed without diapause at 28 and $30^{\circ} \mathrm{C}$; less than $25 \%$ of the individuals entered reproductive diapause at $16-24^{\circ} \mathrm{C}$; however, $46.1 \%$ of the individuals entered diapause at $12^{\circ} \mathrm{C}$, suggesting that low temperature also had a relatively important influence on the determination of diapause. The photoperiodic response curves indicate that this species is a typical short-day species. The critical day-lengths at 20,24 and $28^{\circ} \mathrm{C}$ were $13.2,13.6$ and $13.8 \mathrm{~h}$, respectively. Transferring them from $16 \mathrm{~L}$ : $8 \mathrm{D}$ to $12 \mathrm{~L}: 12 \mathrm{D}$ or vice versa at different ages and/or stages during their development revealed that the photoperiod experienced by adults during the first 11 days might be important for diapause determination, even though an effect of photoperiod on the larval and pupal stages can not be excluded. Transferring individuals kept at a photoperiod of $12 \mathrm{~L}: 12 \mathrm{D}$ from $25^{\circ} \mathrm{C}$ to $12^{\circ} \mathrm{C}$ or vice versa at different ages and/or stages during their development revealed that the temperature cue for diapause is mainly perceived by the late instar larvae and pupae.
\end{abstract}

\section{INTRODUCTION}

Diapause plays a crucial role in survival during unfavourable seasons and the synchronization of the life cycles of the overwhelming majority of insect species in the temperate zone. Many species can detect the onset of harsh conditions and enter diapause by responding to more than one environmental stimulus (Tauber et al., 1986; Danks, 1987). For most short day-length species in the temperate zone, summer diapause is induced by long day-length and high temperature, whereas winter diapause is often controlled by low temperature (Tauber et al., 1986; Danks, 1987; Xue et al., 2001, 2002; Wang et al., 2004).

The brassica leaf beetle, Phaedon brassicae Baly, is widely distributed in East and South Asia, including Korea, Japan, China, Vietnam and India (Ge et al., 2002). This species of beetle mainly feeds on cruciferous vegetables and causes damage in China (Cheo \& Ling, 1943; Li et al., 2000; Xu \& Jiang, 2001) and Japan (Matsumoto \& Fujimoto, 2003). In the region of the Yangtze River in China, this beetle can complete one generation in spring and two generations in autumn. Therefore, there are two distinct infestation peaks in the field, one in April and the other from September to November (Xu \& Xu, 1994). Earlier literature presumed that this beetle aestivated as adults due to lack of food and high temperature from the end of June to the middle of August, and hibernated as adults from early December to the end of February the following year; and pointed out that only adults can sur- vive the bitter cold of winters and the hot of summers (Cheo \& Ling, 1943). However, field investigations showed that the immature stages can also survive in winter. Moreover, feeding and ovipositing is recorded occasionally in mild winters and at the height of summers, but no immature stages have been recorded in summer (Xu \& $\mathrm{Xu}, 1994,1996,2000)$. These observations suggest that this species is a short day species and its life history is very complicated. The seasonal adaptation of this beetle is unclear. The effect of photoperiod and temperature on diapause was unknown, even though such information is essential for accurately predicting the timing of dormancy, development and reproduction in the field (Tauber et al., 1986; Danks, 1987).

In the present study, the role of photoperiod and temperature in diapause induction in this beetle was examined in an attempt to understand its complex life history.

\section{MATERIAL AND METHODS}

\section{Experimental insects}

The $P$. brassicae were collected from pakchoi cabbage, Brassica chinesis, growing in fields in early April and early September in Wuhan, Hubei Province, P. R. China $\left(114^{\circ} 19^{\prime} \mathrm{E}\right.$, $\left.30^{\circ} 33^{\prime} \mathrm{N}\right)$. The adults were fed fresh leaves of the pakchoi cabbage in transparent plastic containers $(15.0 \mathrm{~cm}$ wide and $7.5 \mathrm{~cm}$ deep) and allowed to oviposit under natural conditions. The temperature was about $20^{\circ} \mathrm{C}$ with a natural day-length of around $12.5 \mathrm{~h}$. The eggs were collected every day and kept at $25^{\circ} \mathrm{C}$ and $12 \mathrm{~L}: 12 \mathrm{D}$, and the newly hatched larvae transferred to con-

\footnotetext{
* Corresponding author; e-mail: ioir@mail.hzau.edu.cn
} 


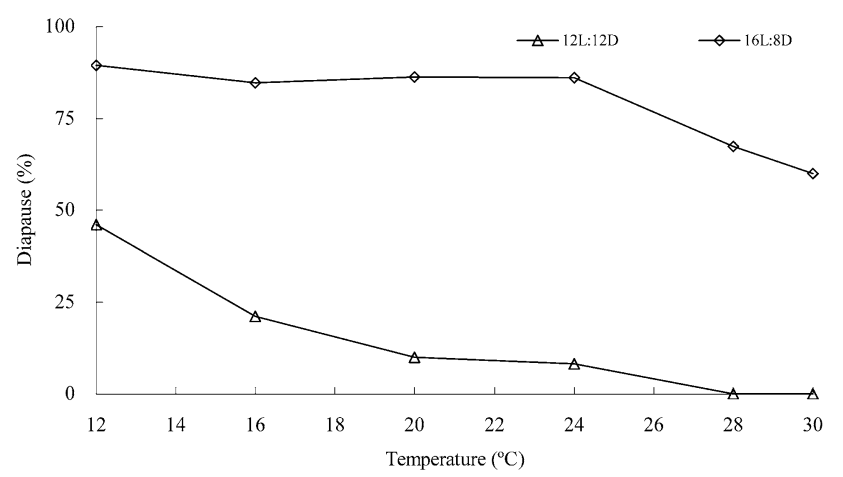

Fig. 1. Diapause incidence in individuals of the spring population of Phaedon brassicae reared at various temperatures under either a $16 \mathrm{~L}: 8 \mathrm{D}(\mathrm{n}=55-94$ for each point $)$ or $12 \mathrm{~L}: 12 \mathrm{D}$ $(\mathrm{n}=62-112$ for each point) photoperiod.

tainers for the experiments. The larvae were fed fresh leaves of pakchoi cabbage and checked daily.

\section{Experimental procedure}

In the region of the Yangtze River, this beetle aestivates as an adult from the end of June to mid-August (mean temperature is about $28^{\circ} \mathrm{C}$ and day-length is longer than $14 \mathrm{~h}$ ) and hibernates as an adult from early December to the end of February the following year (mean temperature is less than $10^{\circ} \mathrm{C}$ and day-length less than $12 \mathrm{~h}$ ) (Cheo \& Ling, 1943). Therefore, the effect of photoperiod and temperature on diapause induction was evaluated by rearing the newly hatched larvae (less than $24 \mathrm{~h}$ old) at various temperatures $\left(12,16,20,24,28\right.$ or $\left.30^{\circ} \mathrm{C}\right)$ and two photoperiods (12L : 12D or 16L : 8D). In another series of experiments on the photoperiodic induction of diapause, a greater range of photoperiods, from LL (continuous light) to DD (continuous darkness) at 20,24 or $28^{\circ} \mathrm{C}$, were used.

To determine the photoperiodic sensitive stage of this species, a temperature of $25^{\circ} \mathrm{C}$ was used. The larvae were initially reared at $12 \mathrm{~L}: 12 \mathrm{D}$ (or $16 \mathrm{~L}: 8 \mathrm{D}$ ) and then transferred at different ages and/or stages to $16 \mathrm{~L}: 8 \mathrm{D}$ (or 12L : 12D) until diapause determination. Temperatures of 12 or $25^{\circ} \mathrm{C}$ were combined with a photoperiod of 12L : 12D (the most effective diapause-averting photoperiod) to determine the sensitive stage for the temperature response. The larvae were reared at $25^{\circ} \mathrm{C}\left(\right.$ or $\left.12^{\circ} \mathrm{C}\right)$, and then transferred at different stages to $12^{\circ} \mathrm{C}$ ( or $25^{\circ} \mathrm{C}$ ) until diapause determination.

In the field, most of the late instar larvae occurred in midOctober. The adults entered diapause once they emerged. In order to determine whether these larvae responded to the diapause-inducing stimuli, the late instar larvae of the second generation in autumn were collected from the field in midOctober and reared under various combinations of photoperiod and temperature until diapause determination. Only the larvae that burrowed into the soil to pupate within 1-2 day(s) of collection were selected for this experiment.

All the experiments were carried out in climate cabinets (SPX-250IC, Shanghai, Boxun Medical Instrument Manufacturer of Shanghai) equipped with three fluorescent $30 \mathrm{~W}$ tubes. The light intensity was about $2.0 \mathrm{~W} \cdot \mathrm{m}^{-2}$, variation in temperatures was $\pm 1{ }^{\circ} \mathrm{C}$, and relative humidity about $70 \% \pm 10 \%$. The scotophase was controlled manually by enclosing the containers in opaque hoods. Each treatment consisted of 1 or 2 containers with about 50 individuals in each.

\section{Diapause determination}

The adults were dissected under a stereomicroscope on the 35 th $\left(12^{\circ} \mathrm{C}\right), 25$ th $\left(16^{\circ} \mathrm{C}\right), 20$ th $\left(20^{\circ} \mathrm{C}\right)$ or 15 th $\left(24-30^{\circ} \mathrm{C}\right)$ day

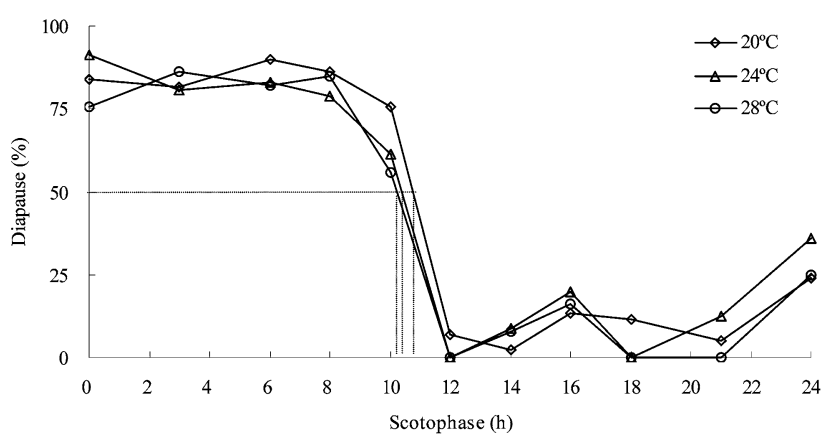

Fig. 2. Photoperiodic response curves for diapause induction in individuals of the autumn population of Phaedon brassicae. $\mathrm{n}$ $=60-118$ for each point at $20^{\circ} \mathrm{C}, 50-88$ at $24^{\circ} \mathrm{C}$ and $52-102$ at $28^{\circ} \mathrm{C}$.

after adult emergence. Dissection date was decided based on the results of a preliminary experiment. Diapause status of the females was judged based on the state of development of ovaries and size of the fat body (unpublished data). Females with no visible previtellogenic oocytes and no visible yolk uptake were considered to be in reproductive diapause. The accessory glands, lateral ejaculatory duct, common ejaculatory duct and ejaculatory sac were poorly developed in diapausing males; in contrast, they were obviously swollen in reproductive males. In addition, the fat body in diapausing adults was larger and darker yellow in colour, and smaller and lighter yellow in colour in reproductive adults.

\section{RESULTS}

\section{Effect of temperature on diapause induction}

The effects of temperature on the induction of diapause were examined under both a long photoperiod of 16L : $8 \mathrm{D}$ and a short photoperiod of 12L : 12D (Fig. 1). Under $16 \mathrm{~L}: 8 \mathrm{D}$, more than $80 \%$ of the individuals entered diapause at $12,16,20$ and $24^{\circ} \mathrm{C}$; even at the high temperatures of 28 and $30^{\circ} \mathrm{C}$ the proportion entering diapause was not less than $60 \%$, indicating that the incidence of diapause in this beetle mainly depended on photoperiod. Under $12 \mathrm{~L}: 12 \mathrm{D}$, virtually no beetles entered diapause at 28 and $30^{\circ} \mathrm{C}$; less than $25 \%$ at 16,20 and $24^{\circ} \mathrm{C}$; however, $46 \%$ entered diapause at $12^{\circ} \mathrm{C}$, suggesting that low temperature has a relatively important influence on the determination of diapause.

\section{Photoperiodic response curves}

Photoperiodic response curves for diapause induction in P. brassicae at 20,24 and $28^{\circ} \mathrm{C}$ were similar. Photophases greater than $12 \mathrm{~h}$ induced most of the adults to enter diapause, whereas those less than $12 \mathrm{~h}$ induced adults to develop without diapause (Fig. 2). The results indicate that the photoperiodic response in this species is a typical short-day type. The critical day-lengths at 20, 24 and $28^{\circ} \mathrm{C}$ were $13.2,13.6$ and $13.8 \mathrm{~h}$, respectively.

\section{The photoperiodic sensitive stage for diapause induction}

Transferring individuals at $25^{\circ} \mathrm{C}$ from a short photoperiod of $12 \mathrm{~L}: 12 \mathrm{D}$ to a long photoperiod of $16 \mathrm{~L}: 8 \mathrm{D}$ or vice versa at different times after hatching, resulted in mirror image response curves (Fig. 3). The effect of pho- 


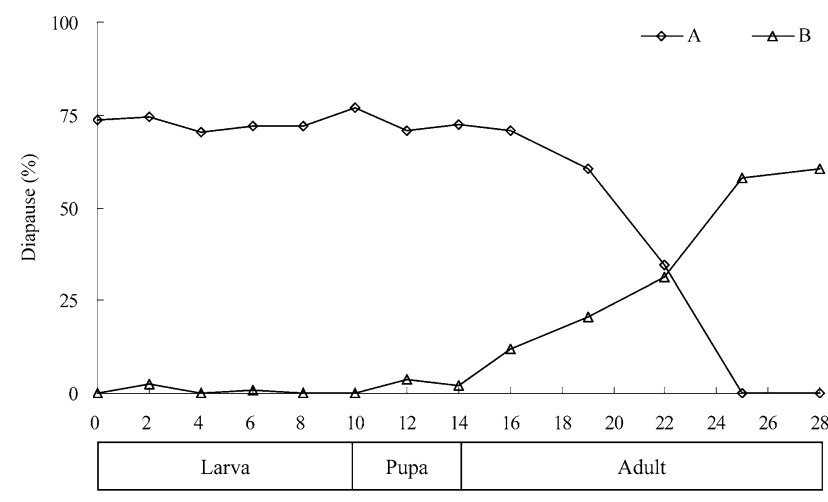

Days of transfer

Fig. 3. The incidence of diapause in individuals of the autumn population of Phaedon brassicae kept at $25^{\circ} \mathrm{C}$. A: Insects were reared at $12 \mathrm{~L}: 12 \mathrm{D}$, and then transferred at different stages and/or ages to $16 \mathrm{~L}: 8 \mathrm{D} ; \mathrm{n}=54-96$ for each point. B: Insects were reared at $16 \mathrm{~L}: 8 \mathrm{D}$, and then transferred at different stages and/or ages to $12 \mathrm{~L}: 12 \mathrm{D} ; \mathrm{n}=55-109$ for each point.

toperiod on diapause incidence was similar in the first 14 days in both experiments $(70.5-76.9 \%$ diapause for the transfer from short day-length to long day-length, Fig. $3 \mathrm{~A} ; 0-3.6 \%$ from long day-length to short day-length, Fig. 3B), suggesting that the first 14 days exposure to short or long day-length has a limited role in the determination of diapause. Then the incidence of diapause gradually declined or increased with the increase in the number of short- or long-day cycles until the 25 th day. According to laboratory observation at $25^{\circ} \mathrm{C}$ and $12 \mathrm{~L}: 12 \mathrm{D}$, the duration of development of the larvae is about 10 days, pupae about 4 days, and the pre-reproductive period about 8 days. Therefore, the results indicate that the photoperiodic experience during the first 11 days of the adult stage might be important for diapause induction in this species, and that an effect of photoperiod on the larval and pupal stages is not excluded. However, in the present experiment, the beetles transferred on the 25th and 28th day only experienced 4 and 1 day, respectively, of 12L : $12 \mathrm{D}$ before dissection (Fig. 3B), thus some immature

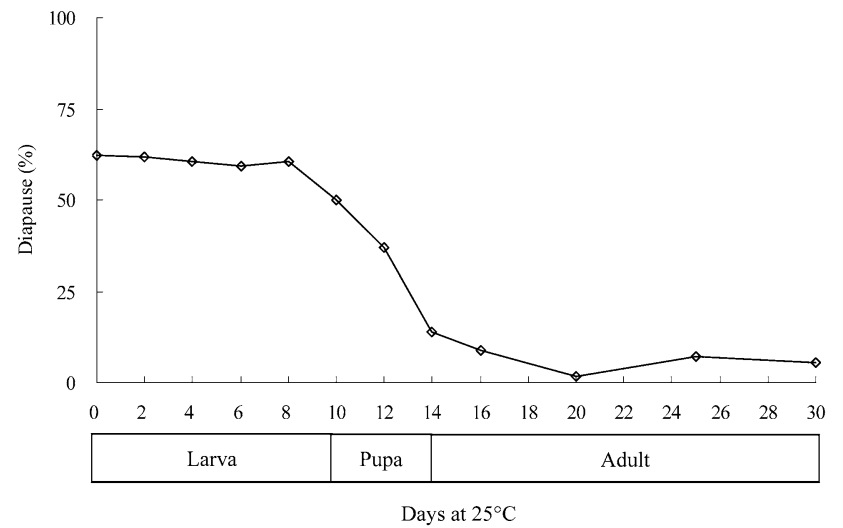

Fig. 4. The incidence of diapause in individuals of the spring population of Phaedon brassicae at 12L : 12D. Insects were reared at $25^{\circ} \mathrm{C}$ and transferred at different stages in their development to $12^{\circ} \mathrm{C} . \mathrm{n}=53-119$ for each point.

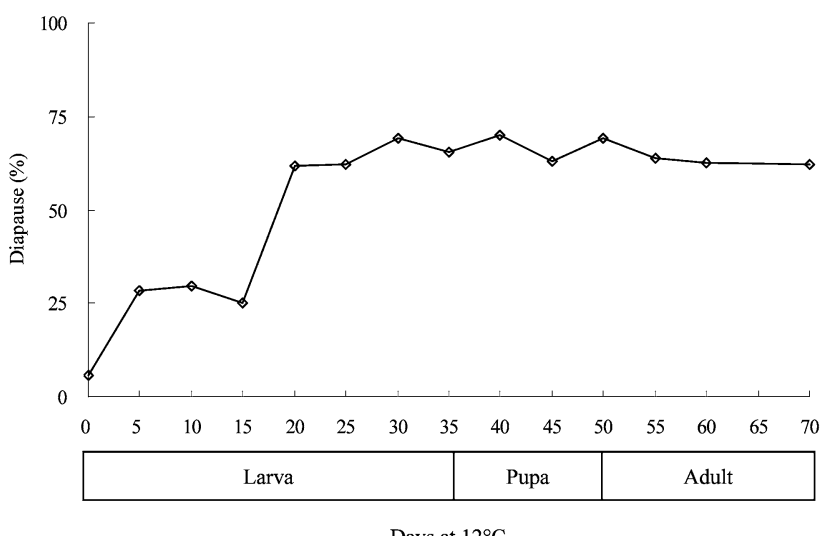

Days at $12^{\circ} \mathrm{C}$

Fig. 5. The incidence of diapause in individuals of the spring population of Phaedon brassicae at 12L : 12D. Insects were reared at $12^{\circ} \mathrm{C}$ and transferred at different stages in their development to $25^{\circ} \mathrm{C} . \mathrm{n}=44-116$ for each point.

adults were probably considered as diapausing individuals.

\section{The sensitive stage to temperature for diapause induction}

By transferring individuals at $12 \mathrm{~L}: 12 \mathrm{D}$ from a high temperature of $25^{\circ} \mathrm{C}$ to a low temperature of $12^{\circ} \mathrm{C}$ or vice versa at different times after hatching, the incidence of diapause among the individuals transferred on the 8th to 16th day gradually declined with the increase in the number of days exposed to $25^{\circ} \mathrm{C}$ (Fig. 4). These results indicate that the proportion of diapause was affected by the temperature experienced by the late instar larvae and pupae. The incidence of diapause gradually increased with the increase in the number of days exposed to $12^{\circ} \mathrm{C}$ during the first 20 days of the larval stage (Fig. 5), showing that the incidence of diapause was affected by the temperature experienced by the larvae. These results suggest that the sensitivity to temperature for diapause induction mainly occurred during the late instar larval and pupal stages.

\section{Field transfer experiment}

The incidence of diapause was obviously affected by the photoperiod experienced in the laboratory by pupae and adults collected in the field in mid-October (Fig. 6).

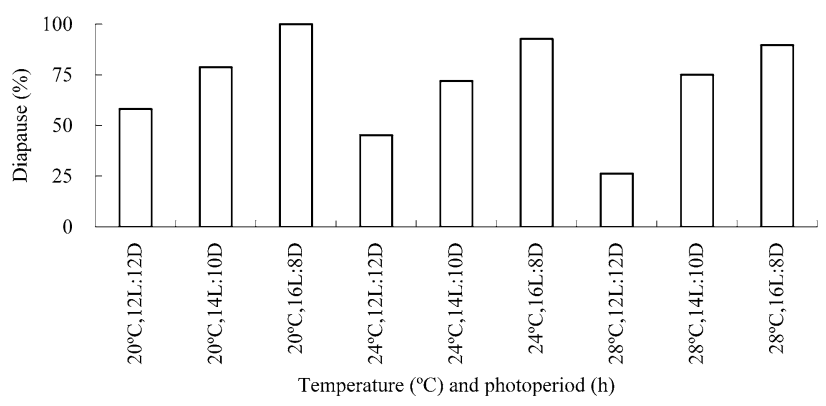

Fig. 6. The incidence of diapause in Phaedon brassicae. The 3 rd instar larvae were collected from the field in mid-October 2005 and reared under various combinations of photoperiods and temperatures. $n=41-62$ for each treatment. 
The incidence of diapause at photoperiods of 14L : 10D and $16 \mathrm{~L}: 8 \mathrm{D}$ was much higher than at the photoperiod of $12 \mathrm{~L}: 12 \mathrm{D}$ in all temperature treatments, further suggesting that the photoperiod experienced by adults played an important role in the determination of diapause.

The data in Fig. 6 show a high incidence of diapause $(58.1 \%)$ at $20^{\circ} \mathrm{C}, 12 \mathrm{~L}: 12 \mathrm{D}$, compared with Fig. $1(9.9 \%$ diapause), but the larvae in the late experiment experienced a constant temperature of $20^{\circ} \mathrm{C}$, suggesting that the late instar larvae collected from field responded to diapause-inducing stimuli to some extent. However, the induction of winter diapause might be related to fluctuations in temperature and changes in day-length, because the mean temperature was 23.4 and $17.7^{\circ} \mathrm{C}$ in September and October, and day-length ranged from $12.2 \mathrm{~h}$ to 11.6 h.

\section{DISCUSSION}

In some aestivating insect, temperature is the primary diapause-inducing factor (cue) for summer dormancy (Tauber et al., 1986; Xue et al., 2002; Liu et al., 2006). In other species, temperature regulates the photoperiodic induction of summer diapause and in most cases high temperature favours the induction of summer diapause (Masaki, 1980); e.g. the cabbage armyworm Mamestra brassicae (Masaki \& Sakai, 1965), chrysomelid beetle Pyrrhalta humeralis (Nakai \& Takeda, 1995), leafmining fly Pegomyia bicolor (Xue et al., 2001). In the brassica leaf beetle, $P$. brassicae, most of the adults entered summer reproductive diapause under long daylength when photophases were greater than $12 \mathrm{~h}$ (Figs 1, 2 ). These findings indicate that the induction of summer diapause is mainly regulated by photoperiod. However, unlike the above, high temperature does not enhance the photoperiodic induction of summer diapause in this species, but inhibits the incidence of diapause to some extent. For example, the incidence of diapause declined with increase in temperature (from $86.2 \%$ to $60 \%$ at 24 and $30^{\circ} \mathrm{C}$ ) under a photoperiod of $16 \mathrm{~L}: 8 \mathrm{D}$ (Fig. 1). This is the reason why some adults feed and oviposit from the end of June (average temperature about $25.6^{\circ} \mathrm{C}$ ) to the end of July (average temperature about $28.7^{\circ} \mathrm{C}$ ) in the region of the Yangtse River when food is available (Xu \& $\mathrm{Xu}, 1994)$. In fact, summer diapause in the brassica leaf beetle, $P$. brassicae, can be induced by a moderate temperature because the temperature is about $24^{\circ} \mathrm{C}$ and the day-length about $14 \mathrm{~h}$ in early June in this region. Our present results do not support the notion that this beetle aestivates as an adult in response to high temperature during summer (Cheo \& Ling, 1943).

In the temperate zone, low temperature favours the photoperiodic induction of winter diapause of most long-day insect species (Tauber et al., 1986; Danks, 1987). Moreover, winter diapause induced by low temperature is also reported in some short-day species, e.g. the leaf-mining fly Pegomyia bicolor (Xue et al., 2001) and cabbage beetle Colaphellus bowringi (Xue et al., 2002). In the present experiments, $46.1 \%$ of the adults entered diapause at $12^{\circ} \mathrm{C}, 12 \mathrm{~L}: 12 \mathrm{D}$ (Fig. 1), indicating that low temperature enhances the induction of winter diapause in this beetle. This accords with a previous observation (Cheo \& Ling, 1943). However, there were always some individuals that developed without diapause at low temperatures and short day-lengths (Figs 1 and 6). This implies that some of the overwintering adults are in quiescence rather than diapause during winter. In fact, the individuals that damaged vegetables during winter hatched from the end of September to early October (the mean temperature was 23.4 and $17.7^{\circ} \mathrm{C}$ in September and October, day-length ranged from $12.2 \mathrm{~h}$ to $11.6 \mathrm{~h}$ ). This is the reason why feeding and ovipositing of the adults, and presence of immature stages are observed during winter in the region of the Yangtse River (Xu \& Xu, 1996, 2000).

In the Chrysomelidae, there are three species in which the induction of reproductive diapause occurs mainly in the adult stage and another three species in which it occurs in both the adult and larval stages (Danks, 1987; Xue et al., 2002), however, the role of other stages in the induction of diapause is not totally excluded. Identification of the sensitive stages requires a suitable bioassay for measuring sensitivity to diapause-inducting factors (Tauber et al., 1986), e.g. larval sensitivity to photoperiods controlling adult diapause can be tested by the use of 'neutral' photoperiods (Hodek, 1971). Our results indicate that photoperiod and temperature influence sensitivity to different extents in the incidence of diapause of the brassica leaf beetle. Temperature acts on the late larval instars and pupae, whereas photoperiod acts on the adult stage, although the sensitivities of other stages are not totally excluded. However, the sensitive stages to temperature and photoperiod need further investigation, because there was not enough time for the beetles in the last 2 transfers in Fig. 3B to become reproductive before dissection. The effects of thermal and photoperiodic exposures on the development and depth of diapause are not included in present study.

These responses play an important role in determining the life cycle of $P$. brassicae. Photoperiod control of summer diapause ensures that the beetles enter summer diapause in mid-May (day-length longer than $13.6 \mathrm{~h}$ in Wuhan) and avoid reproduction during adverse summer conditions (the mean temperature is 25.6 and $28.7^{\circ} \mathrm{C}$ in June and July). In fact, food is not available during summer in this region. All cruciferous vegetables are harvested in May and are generally not cultivated again until the end of August. The beetle overwinters from early December to the end of February the following year in response to low temperature, because the mean temperature is less than $6.0^{\circ} \mathrm{C}$ in December, January and February in Wuhan. However, the effects of some other cues on winter diapause induction need to be further verified, because the design of the experiments did not allow photoperiod to be ruled out as a cue (Tauber et al., 1986). Some adults that overwinter in quiescence can resume feeding and reproduction in warm winters, because cruciferous vegetables can overwinter in this region. 
ACKNOWLEDGEMENTS. We thank Q. Sheng and D. You for their assistances with experiments, and $\mathrm{Y}$. Xu for his advice on the language of the manuscript. We also thank I. Hodek for encouraging us to interpret our results in the described manner. The research was supported by grants from the Eleventh Science and Technology Five-year National Program (2006BAD17B08) and China Postdoctoral Science Foundation (20060390864).

\section{REFERENCES}

Cheo M.Z. \& Ling Y. 1943: Life history studies on the cruciferous leaf-beetle (Phaedon brassicae Baly, Coleoptera). Quart. J. Xinnong 3: 50-61 [in Chinese].

Danks H.V. 1987: Insect Dormancy: An Ecological Perspective. Biological Survey of Canada, Ottawa, 439 pp.

GE S.Q., WANG S.Y. \& YANG X.K. 2002: Notes on the genus Phaedon Latreille of China (Coleptera:Chrysomelidae). Acta Zootaxon. Sin. 27: 316-325 [in Chinese].

Hoder I. 1971: Sensitivity of larvae to photoperiods controlling the adult diapause of two insects. J. Insect Physiol. 17: $205-216$.

Li W.F., Gu D.J., Chen Y.G. \& Chen Z.P. 2000: Studies on effects of vegetable varieties on biology of Phaedon brassicae Baly. J. South China Agric. Univ. 21: 38-40 [in Chinese].

Liu Z., Gong P., Wu K., Sun J. \& Li D. 2006: A true summer diapause induced by high temperatures in the cotton bollworm, Helicoverpa armigera (Lepidoptera: Noctuidae). J. Insect Physiol. 52: 1012-1020.

Masaki S. 1980: Summer diapause. Annu. Rev. Entomol. 25: $1-25$.

MASAKI S. \& SAKAI T. 1965: Summer diapause in the seasonal life cycle of Mamestra brassicae Linne (Lepidoptera: Noctuidae). Jap. J. Appl. Entomol. Zool. 9: 191-205.
Mатsumoto E. \& Fusimoto S. 2003: Effect of insecticides on adults of the brassica leaf beetle, Phaedon brassicae Baly, tested by the diet dipping method. Res. Rep. Kagawa Agric. Exp. St. 56: 51-56.

NAKAi T. \& TAKeda M. 1995: Temperature and photoperiodic regulation of summer diapause and reproduction in Pyrrhalta humeralis (Coleoptera: Chrysomelidae). Appl. Entomol. Zool. 30: $295-301$.

Tauber M.J., Tauber C.A. \& Masaki S. 1986: Seasonal Adaptations of Insect. Oxford University Press, New York, 411 pp.

Wang X., GE F., Xue F. \& You L. 2004: Diapause induction and clock mechanism in the cabbage beetle, Colaphellus bowringi (Coleoptera: Chrysomelidae). J. Insect Physiol. 50: 373-381.

XU Y.F. \& JIANG D.Q. 2001: Causes of outbreak in Phaedon brassicae and its control. J. Changjiang Veget. 6: 10 [in Chinese].

XU Y.F. \& XU S.W. 1994: Occurrence and some biological characters of the brassica leaf beetle, Phaedon brassicae Baly. Zhejiang Agr. Sci. 6: 262-264 [in Chinese].

Xu Y.F. \& XU S.W. 1996: Over-wintering stages of Phaedon brassicae Baly. J. Changjiang Veget. 4: 15-16 [in Chinese].

XU Y.F. \& XU S.W. 2000: Note on egg-laying of Phaedon brassicae Baly in winter. J. Shanghai Veget. 3: 44 [in Chinese].

Xue F.S., Zhu X.F. \& Shao Z.Y. 2001: Control of summer and winter diapause in the leaf-mining fly Pegomyia bicolor Wiedemann (Dipt., Anthomyiidae). J. Appl. Entomol. 125: 181-187.

Xue F.S., Spieth H.R., Li A.Q. \& Hua A. 2002: The role of photoperiod and temperature in determination of summer and winter diapause in the cabbage beetle, Colaphellus bowringi (Coleoptera: Chrysomelidae). J. Insect Physiol. 48: 279-286.

Received October 30, 2006; revised and accepted July 17, 2007 